\title{
UNA INMACULADA DE JUAN DE PAREJA
}

\author{
René Jesús Payo HeRnanz \\ Universidad de Burgos
}

\begin{abstract}
En este artículo damos a conocer una pintura inédita firmada por Juan de Pareja, que representa a la Inmaculada, y que se conserva en la iglesia de Santa Lucía de la localidad de El Almiñé (Burgos) y que viene a enriquecer el no demasiado amplio catálogo de este maestro.
\end{abstract}

Palabras clave: Juan de Pareja; Pintura barroca; Inmaculada; El Almiñé.

\section{AN IMMACULATE CONCEPTION BY JUAN DE PAREJA}

The author presents an unpublished painting of the Immaculate Conception signed by Juan de Pareja, preserved in the church of Saint Lucy in the town of El Almiñé (Burgos), thereby enriching the limited catalogue of this master.

Keywords: Juan de Pareja; Baroque painting; Immaculate; El Almiñé.

El pintor Juan Pareja es conocido universalmente gracias al magnífico retrato que de él realizara Velázquez en Roma en 1650 en su segundo viaje a Italia ${ }^{1}$. Su padre, llamado como él, era natural de Antequera (Málaga). Debió nacer en esa localidad o en Sevilla, hacia 1605-1610. De orígenes moriscos y de generación mestiza y color extraño, según Palomino², fue esclavo de Velázquez, durante un largo periodo de tiempo ${ }^{3}$. Quizá entró al servicio del pintor en Sevilla y con él pudo llegar a la corte cuando se trasladó en busca de un futuro más brillante. La tradición señala que, estando al servicio de su maestro en tareas meramente manuales y, sin que éste le permitiera pintar, aprendió a escondidas los secretos de la pintura ${ }^{4}$. Obtuvo la libertad en Roma 1650 aunque, según sus biógrafos más antiguos, continuó sirviendo a Velázquez hasta su muerte e incluso, más allá de ésta, siguió trabajando en la casa de la hija de su antiguo amo y de su yerno Juan Bautista del Mazo5. Debió ser, desde esos momentos, cuando comenzó una actividad profesional independiente, dedicada a la pintura, que le ocuparía las dos últimas décadas de su existencia. Su primer cuadro fechado nos lleva al año 1658. A lo largo de su vida profesional desarrolló un no muy amplio catálogo de obras ${ }^{6}$. Sin embargo, sabemos que debió gozar de un gran prestigio en su época, pues Palomino habló de él de manera encomiástica, mucho más que de otros de los maestros del círculo de Velázquez?

La pintura de Pareja aparece ligada a la de Velázquez, aunque con una técnica más densa y corpórea. Quizá fue en sus producciones como retratista donde siguió más de cerca a su maestro, destacándose el magnífico retrato del arquitecto José Ratés (Museo de Valencia), que fue muy elogiado por Palomino y un retrato de Felipe IV (colección particular americana). Gran calidad presentan también el retrato de Don Martín de Leiva, el Don Alonso de Mora y Villalta (ambos en la Hispanic Society de Nueva York) y el de Agustín de Moreto (Museo Lázaro Gadiano).

\footnotetext{
${ }^{1}$ Montagu, 1983: 683-685.

2 Palomino, 1988: 307.

${ }^{3}$ No debe resultarnos extraño que Velázquez tuviera un esclavo. La esclavitud en la España del siglo XVII, sobre todo en el sur de la Península, fue bastante habitual. Sabemos que otros pintores como Pacheco, Herrera o Murillo fueron igualmente poseedores de esclavos. Domínguez Ortiz hace referencia a algunos interesantes casos de esclavos en Antequera, lugar de donde parece que era originario el padre de Juan de Pareja (Domínguez OrTiz, 1952: 381).

${ }^{4}$ Palomino, 1988: 308.

5 Palomino, 1988: 309.

${ }^{6}$ Gaya Nuño hizo una recopilación de los datos sobre la vida y obra de Juan de Pareja (GAYA NuÑo, 1956: 276). La mejor síntesis sobre la vida y obra de Juan de Pareja es la tesis doctoral de María del Mar Doval Trueba sobre los pintores "velazqueños". En este trabajo inédito se realiza un catálogo del pintor formado por unas 30 obras, de las cuales casi una veintena se encuentran, en la actualidad, en paradero desconocido (Doval TrueBA, 2000: 225-241).

${ }^{7}$ Palomino, 1988: 307-311.
} 
En sus pinturas religiosas, se muestra un tanto ajeno de la contención velazqueña, evidenciándose un notable barroquismo compositivo y una búsqueda de la luminosidad y de la riqueza cromática que supera el estilo de su maestro. Muy probablemente estos rasgos son deudores de otros pintores coetáneos como Rizi y Carreño y, en gran medida, se emparentan con lo que otros artistas, como Claudio Coello, comenzaban a hacer en estos momentos ${ }^{8}$. Quizá sus composiciones más importantes, dentro de este género, sean los óleos la Vocación de San Mateo (Museo del Prado) ${ }^{9}$ y el Bautismo de Cristo (Museo de Huesca), destacándose la primera por su monumentalidad, cuidada composición y sobriedad y la segunda por la estilización de las figuras y por su dinamismo y vigoroso colorido. Muy interesantes son, igualmente, la Comunión de Santa María Egipciaca, la Huida a Egipto (pintura de 1658, conservada, en el Florida Ringling Museum de Sarasota) y los Desposorios Místicos de Santa Catalina (obra de 1669 conservada en la iglesia parroquial de Santa Olaja de Eslonza en León) en las que se evidencia un notable dominio del color y una correcta y movida composición. Igualmente, como veremos, en varias ocasiones se dedicó al tema de la Inmaculada que tan en boga se hallaba en los años centrales del siglo XVII.

En la iglesia de Santa Lucía del pueblo burgalés de El Almiñé (Merindad del Valle de Valdivielso) se conserva un óleo con la representación de una Inmaculada, obra de Juan de Pareja, que hasta ahora era desconocida, y que viene a engrosar el no muy abultado catálogo de este maestro (fig. 1). La primera pregunta que debemos hacernos es cómo pudo llegar a esta localidad esta pintura. A pesar de lo alejado que se encontraba El Almiñé de Madrid, sabemos que, a lo largo del siglo XVII, muchos personajes de la Merindad ocuparon importantes cargos en la Corte. A buena parte de la hidalguía local no le quedó más remedio, para intentar progresar socialmente, que trasladarse a la capital del reino para desempeñar cargos administrativos. Casi todos los que lograron éxitos en Madrid continuaron manteniendo relaciones con su solar natal, siendo frecuentes los envíos de productos artísticos a sus lugares de procedencia ${ }^{10}$. Uno de los personajes que destacó en el Madrid de mediados del siglo XVII fue don Juan de San Martín, Caballero de la Orden de Santiago, natural de Valdenoceda, que ocupó el cargo de Ayudante de Cámara de Felipe IV y camarero del marqués del Carpio. Sabemos que este ilustre hidalgo recordó siempre su solar natal y donó a la iglesia parroquial del mismo una serie de interesantes pinturas madrileña aún conservadas y de notable calidad ${ }^{11}$. Otro ejemplo de este tipo de comportamiento lo tenemos en la familia Porres, hidalgos de la Merindad, que también desempeñaron destacados cargos administrativos en Madrid y que igualmente donaron a la cercana iglesia de Condado de Valdivielso algunas obras artísticas salidas de talleres cortesanos. En la propia localidad de El Almiñé existieron algunas familias con conexiones madrileñas, como los Zorrilla o los Fernández de Valdivielso, que muy bien pudieron ser quienes adquirieron, en la Corte, esta pintura de Juan de Pareja donándola posteriormente a la iglesia ${ }^{12}$. En cualquier caso, hasta el momento, no hemos conseguido documentar la forma en que se produjo la llegada de esta interesante Inmaculada a El Almiñé.

Juan de Pareja realizó, al menos en otras dos ocasiones, pinturas con el tema de la Inmaculada. Una se conserva en una colección privada madrileña y otra, actualmente en paradero perdido aunque conocida a través de fotografías, sabemos que perteneció a la Colección Ordóñez de Madrid ${ }^{13}$. Ambas, aún representando el mismo tema, responden a modelos diferentes entre sí y en relación con la de El Almiñé.

\footnotetext{
${ }^{8}$ Pérez SÁnchez, 1992: 239.

${ }^{9}$ Doval Trueba, 2005: 75-88.

${ }^{10}$ Huidobro Serna y García Sáinz de Baranda, 1930.

${ }^{11}$ Se trata de una Flagelación, una Inmaculada y una copia de la Virgen de la Soledad de los Mínimos de la Victoria de Madrid y que deben ser sólo una parte de la colección que llegaría a adquirir en Madrid.

12 Arce Garmilla, 2005.

${ }^{13}$ Esta pintura fue publicada por Lafuente Ferrari (LAFUENTE FerRari, 1941: 22-27).
} 


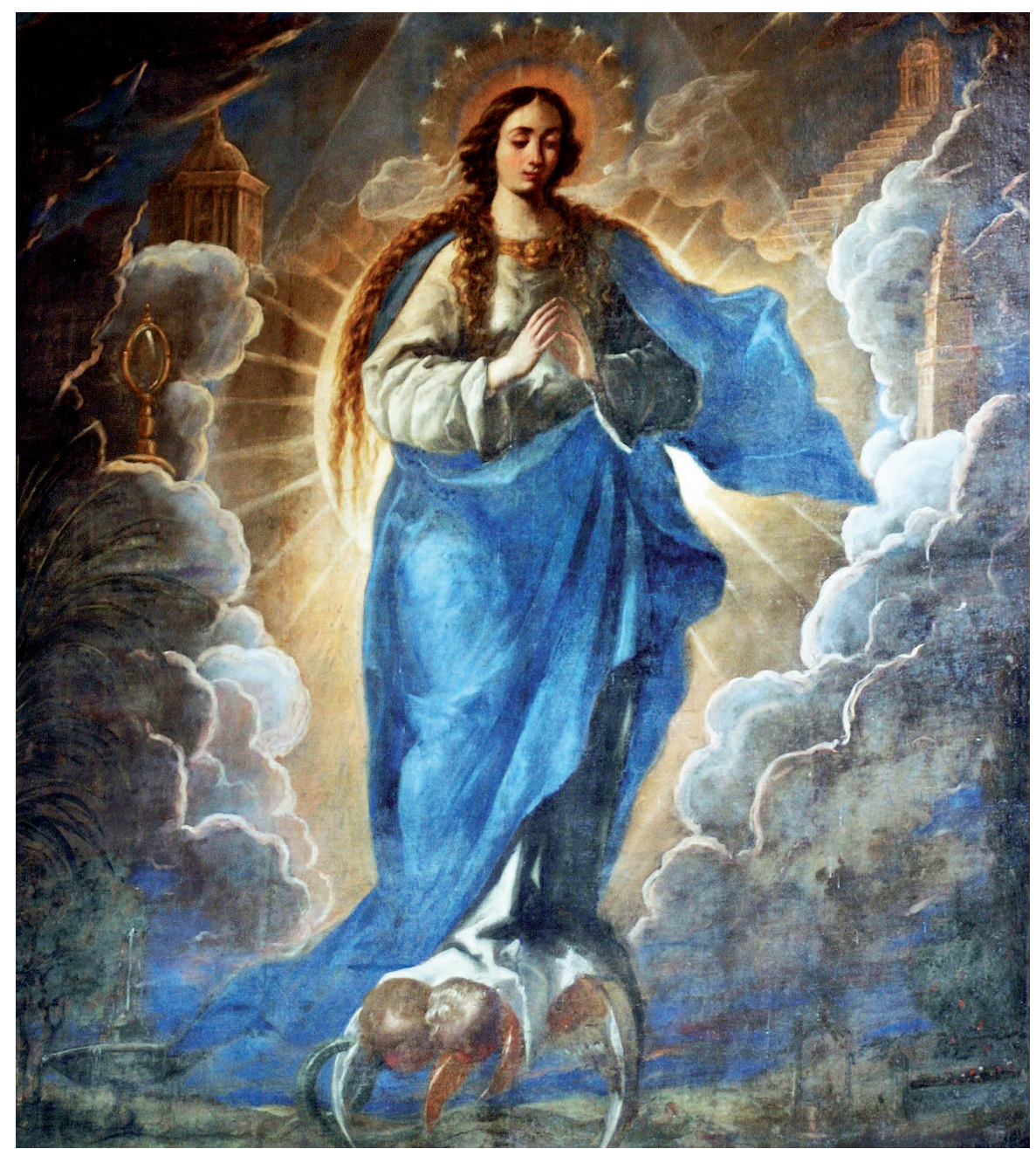

Fig. 1. Juan de Pareja. Inmaculada. El Almiñé (Burgos).

La Inmaculada, que ahora presentamos, es un pintura casi cuadrangular (1,62 x 1,52 m.). En el ángulo inferior izquierdo se lee la firma del maestro: Juan de Pareja $f(. .)$.8 . Lamentablemente se ha perdido parte de la pintura en la zona de la fecha, por lo que no podemos determinar si el momento en que se ejecutó este lienzo fue en 1658 o 1668. La Virgen se ubica sobre un creciente lunar invertido, con dos cabezas de angelitos, muy parecido al de la Inmaculada de la antigua Colección Ordóñez. Tiene forma alargada y viste la clásica túnica blanca y manto azul que queda recogido en el brazo izquierdo y que vuela movido por el viento tanto a la altura del hombro derecho como en los pies. En el pecho, la túnica presenta un cuello bordado rematado por un gran broche dorado a modo de angelito. Las manos aparecen suavemente unidas por los dedos en actitud de oración y la cabeza se encuentra ligeramente girada hacia la derecha, con la mirada baja. Las facciones del rostro parecen encontrarse más próximas a las de la pintura de la antigua Colección Ordóñez. El cabello cae en rizados mechones dorados sobre el pecho y los hombros de una forma muy similar a como lo hace en las dos pinturas antedichas (fig. 2). 


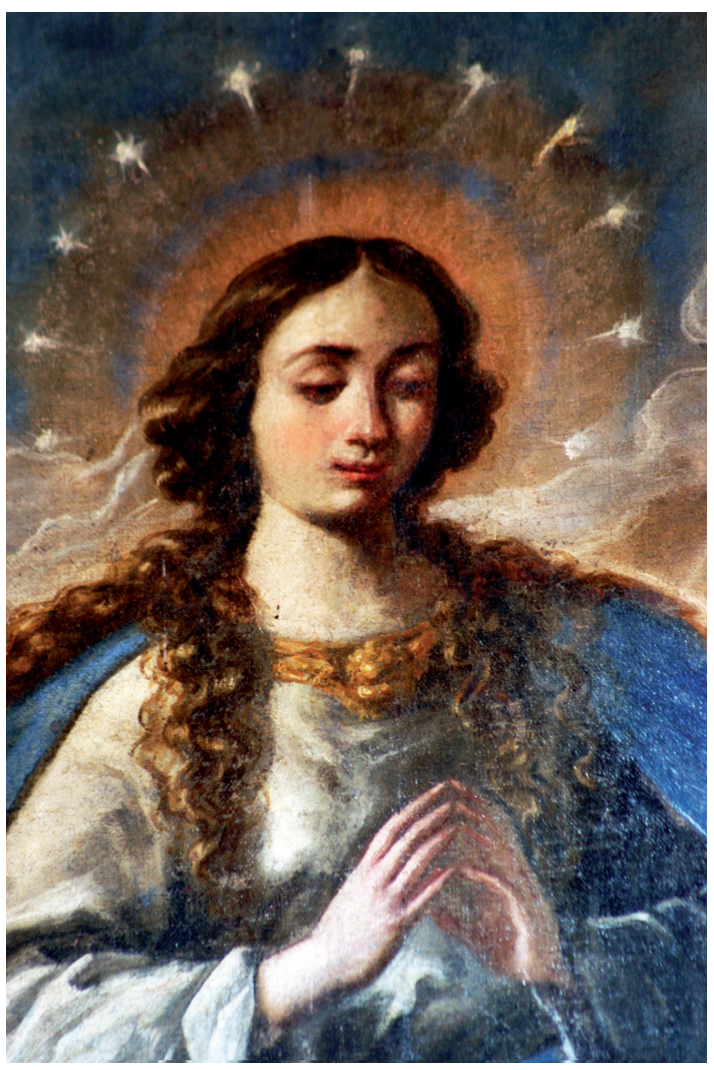

Fig. 2. Juan de Pareja. Detalle de la Inmaculada. El Almiñe (Burgos).

más al rigor dibujístico. En ambos casos, la figura de María aparece con las manos separadas, ubicándose la derecha sobre el pecho y la izquierda alejada del cuerpo. La de El Almiñé sería un modelo intermedio entre ambas. Presenta un cierto movimiento, a través de los ropajes, aunque el cuerpo se caracteriza por su quietud. La paleta cromática y la técnica suelta se hallan próximas a la primera pintura inmaculista a la que hicimos referencia. La pintura de El Almiñé denota un conocimiento bastante amplio de otras realizaciones que, con el mismo tema, estaban realizando otros grandes pintores del momento como Francisco Rizi ${ }^{14}$.
La imagen se ubica sobre un fondo de nubes que se despejan en el centro, formando un óvalo, donde se sitúa la Virgen. En la parte trasera aparece un sol circular del que surgen unos rayos que bordean la parte superior de su cuerpo. Un haz de luz, en forma triangular y procedente del cielo, corona la figura de la Virgen. Entre las nubes aparecen los clásicos atributos marianos vinculados a las letanías lauretianas, algunos de los cuales son semejantes a los de la Inmaculada de la antigua Colección Ordóñez.

Correspondería esta obra de El Almiñé a un tercer modelo de Inmaculada que no se adecúa a ninguno de las otras dos pinturas inmaculistas a las que nos hemos referido anteriormente. La primera se caracterizaría por su gran movimiento, por la vaporosa utilización del color y por un exultante cromatismo (fig. 3). La segunda, que solamente es conocida a través de reproducciones en blanco y negro, es más contenida y parece adecuarse

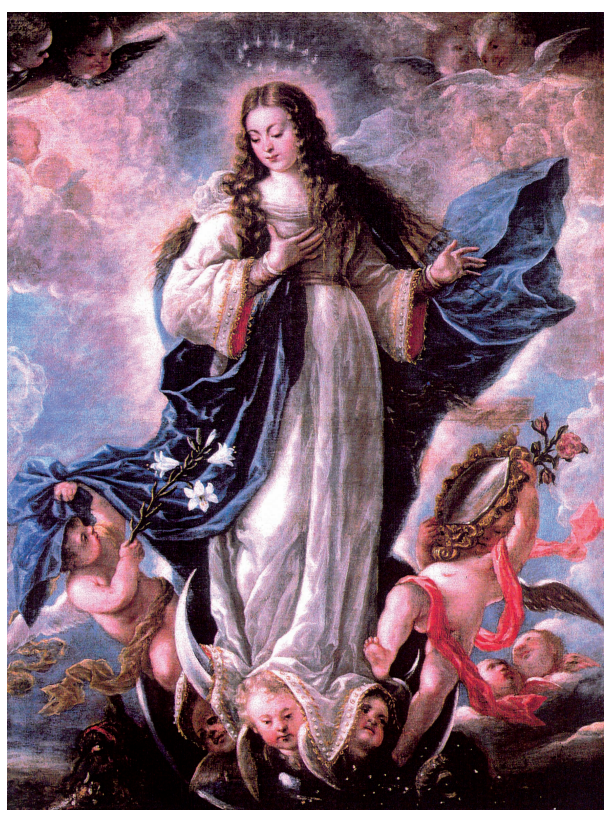

Fig. 3. Juan de Pareja. Inmaculada. Colección particular. Madrid.

${ }^{14}$ Encontramos algunas semejanzas con la Inmaculada de Rizi del Museo de Bellas Artes de Cádiz, en concreto en el tratamiento de los cabellos. En la pose encontramos semejanzas con la Inmaculada de este maestro del Museo del Prado (Agüera Ros, 1982: 193-196). 


\section{BIBLIOGRAFÍA}

Agüera Ros, José Carlos, "Una Inmaculada inédita de Francisco Rizi en Murcia”, Anales de la Universidad de Murcia, Vol. 40, no 3-4, pp. 193-196.

Arce Garmilla, Jesús, El Almiñé, Burgos, 2005.

Domínguez Ortiz, Antonio, "La esclavitud en Castilla en la Edad Moderna", en Estudios de Historia Social de España, T. II, 1952, p. 381.

Doval Trueba, María del Mar, Los "velazqueños": pintores que trabajaron en el taller de Velázquez, Tesis Doctoral inédita dirigida por Alfonso E. Pérez Sánchez, Universidad Complutense, Madrid, pp. 225-241.

Doval Trueba, María del Mar, "Velázquez y la vocación de San Mateo", Boletín del Museo e Instituto Camón Aznar, $\mathrm{N}^{\circ} \mathrm{XCV}, 2005$, pp. 75-88.

Gaya Nuño, Juan Antonio, "Revisiones sexcentistas: Juan de Pareja”, Archivo Español de Arte, N N 120, 1956, p. 276.

Huidobro Serna, Luciano y García Sáinz de Baranda, Julián: Apuntes descriptivos, históricos y arqueológicos de la Merindad de Valdivielso, Burgos, 1930.

Lafuente Ferrari, Enrique, "Cuadros de maestros menores madrileños (Pareja, Solís, Arredondo, García Hidalgo)", Arte Español, 1941, pp. 22-27.

Montagu, Jennifer, "Velázquez Marginalia: his slave Juan de Pareja and his illegitimate son Antonio", Burlington Magazine, 1983, pp. 683-685.

Palomino, Antonio, El Museo Pictórico y la Escala Óptica El Parnaso Español Pintoresco y Laureado, Aguilar, Madrid, 1988, p. 307.

Pérez Sánchez, Alfonso E., Pintura barroca en España, Cátedra, Madrid, 1992, p. 239.

Fecha de recepción: 7-X-2011

Fecha de aceptación: 29-XII-2011 